Annuaire suisse de politique de développement

13 | 1994

Annuaire Suisse - Tiers Monde 1994

\title{
3. Bibliographie Literaturverzeichnis
}

\section{René Barbey}

\section{OpenEdition}

\section{Journals}

Édition électronique

URL : http://journals.openedition.org/aspd/1069

DOI : 10.4000/aspd.1069

ISSN : 1663-9669

\section{Éditeur}

Institut de hautes études internationales et du développement

\section{Édition imprimée}

Date de publication : 1 janvier 1994

Pagination : 303-305

ISSN : 1660-5934

\section{Référence électronique}

René Barbey, «3. Bibliographie Literaturverzeichnis », Annuaire suisse de politique de développement [En ligne], 13 | 1994, mis en ligne le 19 décembre 2012, consulté le 08 septembre 2020. URL : http:// journals.openedition.org/aspd/1069; DOI : https://doi.org/10.4000/aspd.1069 


\section{Bibliographie}

\section{Literaturverzeichnis}

René Barbey

avec la collaboration de

Viviane Maislisch 


\section{Einleitung}

Das vorliegende Literaturverzeichnis umfasst Veröffentlichungen von Oktober 1992 bis Oktober 1993. Diese behandeln hauptsächlich die Beziehungen der Schweiz zur Dritten Welt (erster Teil, in drei Abschnitte unterteilt). Im weiteren findet sich auch eine Auswahl von Texten über die Dritte Welt und zur Entwicklungsthematik, die in der Schweiz herausgebracht oder von Schweizern veröffentlicht wurden (zweiter Teil).

\section{Gliederung}

Referenznummern

\section{Teil : $\quad$ Beziehungen Schweiz-Dritte Welt}

Abschnitt 1: Verfasser und anonyme Werke

Abschnitt 2: Private Institutionen

Abschnitt 3 : Publikationen der Eidgenossenschaft

$101-123$

A. Bund

124-134

B. Direktion für Entwicklungszusammenarbeit und humanitäre Hilfe

2. Teil : Auswahl schweizerischer Werke über die Dritte Welt/Entwicklungspolitik

Anmerkung : Die Gliederung des erstens Teils in drei Abschnitte wurde der Vereinfachung halber vorgenommen und soll der Leserin/dem Leser eine bessere Übersicht vermitteln. Veröffentlichungen des Bundes und der privaten Institutionen, welche die Unterschrift eines Verfassers tragen, sind im 1. Abschnitt des 1. Teils und im 2. Teil aufgeführt.

\section{Abkürzungen}

(All.)

DDA

FF

RO
Dokumente auch in deutscher Sprache erhältlich

DEH - Direktion für Entwicklungszusammenarbeit und humanitäre Hilfe

Bundesblatt (Feuille fédérale)

Sammlung der Bundesgesetze (Recueil officiel des lois fédérales)

In den übrigen Fällen wurden die vollständigen Titel angeführt. 


\section{Introduction}

La présente bibliographie contient les références d'octobre 1992 à octobre 1993. Elles concernent principalement les Relations Suisse-Tiers Monde (Partie I, subdivisée en 3 sections). Nous avons également signalé une Sélection de textes (parus en Suisse ou publiés par des Suisses) sur le Tiers Monde et le développement (Partie II).

\section{Classification}

$\mathrm{N}^{\circ}$ des références

\section{Partie 1: $\quad$ Relations Suisse-Tiers Monde}

Section 1: $\quad$ Auteurs et titres anonymes

Section 2: Institutions privées auteurs

Section 3: $\quad$ Publications gouvernementales

A. Confédération

B. Direction de la coopération au développement et de l'aide humanitaire, D.D.A.

Partie II : $\quad$ Sélection de textes suisses sur le Tiers Monde/Développement

Remarque : La distinction entre les trois sections de la 1ère partie a pour but de simplifier la présentation. Les publications de la Confédération et des institutions privées, signées par des personnes physiques, figurent dans la section 1 de la partie I et dans la partie II.

\section{Abbréviations}

(All.) Document disponible également en allemand

DDA Direction de la coopération au développement et de l'aide humanitaire

FF Feuille fédérale

RO Recueil officiel des lois fédérales

Dans les autres cas, nous avons mis les intitulés complets. 